\title{
Crop rotation and genetic resistance reduce risk of damage from Fusarium wilt in lettuce
}

\author{
by Jeness C. Scott, Thomas R. Gordon, Sharon \\ C. Kirkpatrick, Steven T. Koike, Michael E. \\ Matheron, Oswaldo E. Ochoa, Maria J. Truco \\ and Richard W. Michelmore
}

\section{Fusarium wilt of lettuce, caused by the} soilborne fungus Fusarium oxysporum f. sp. lactucae, affects all major lettuce production areas in California and Arizona. In trials at UC Davis, we found that lettuce cultivars differ significantly in susceptibility to the disease, with some leaf and romaine types highly resistant under all test conditions. For more susceptible cultivars, disease severity is strongly influenced by inoculum levels and ambient temperature. Management of Fusarium wilt requires an integrated approach that includes crop rotation to reduce soil inoculum levels and the use of resistant cultivars during the warmest planting windows.

\footnotetext{
T ettuce is the fifth most valuable ag_ricultural commodity in California, with a farm-gate value of over $\$ 1.7$ billion in 2009. Successful production requires effectively managing diseases that reduce yield, lower quality and generate control costs. Lettuce (Lactuca sativa) is subject to diseases such as downy mildew, caused by Bremia lactucae, and lettuce drop, caused by Sclerotinia spp. (both resident in California for many years), as well as a more recent problem, Fusarium wilt.

Fusarium wilt was discovered in California in 1990, when plants with symptoms that ranged from mild stunting to complete collapse were observed in two fields near Huron, in the San Joaquin Valley. Diseased plants had severely rotted taproots, from which a fungus identified as Fusarium oxysporum was isolated (Hubbard and Gerik 1993). F. oxysporum is widespread in agricultural soils throughout the world and is commonly isolated from the roots of healthy plants. Most strains are weak parasites that grow only
}

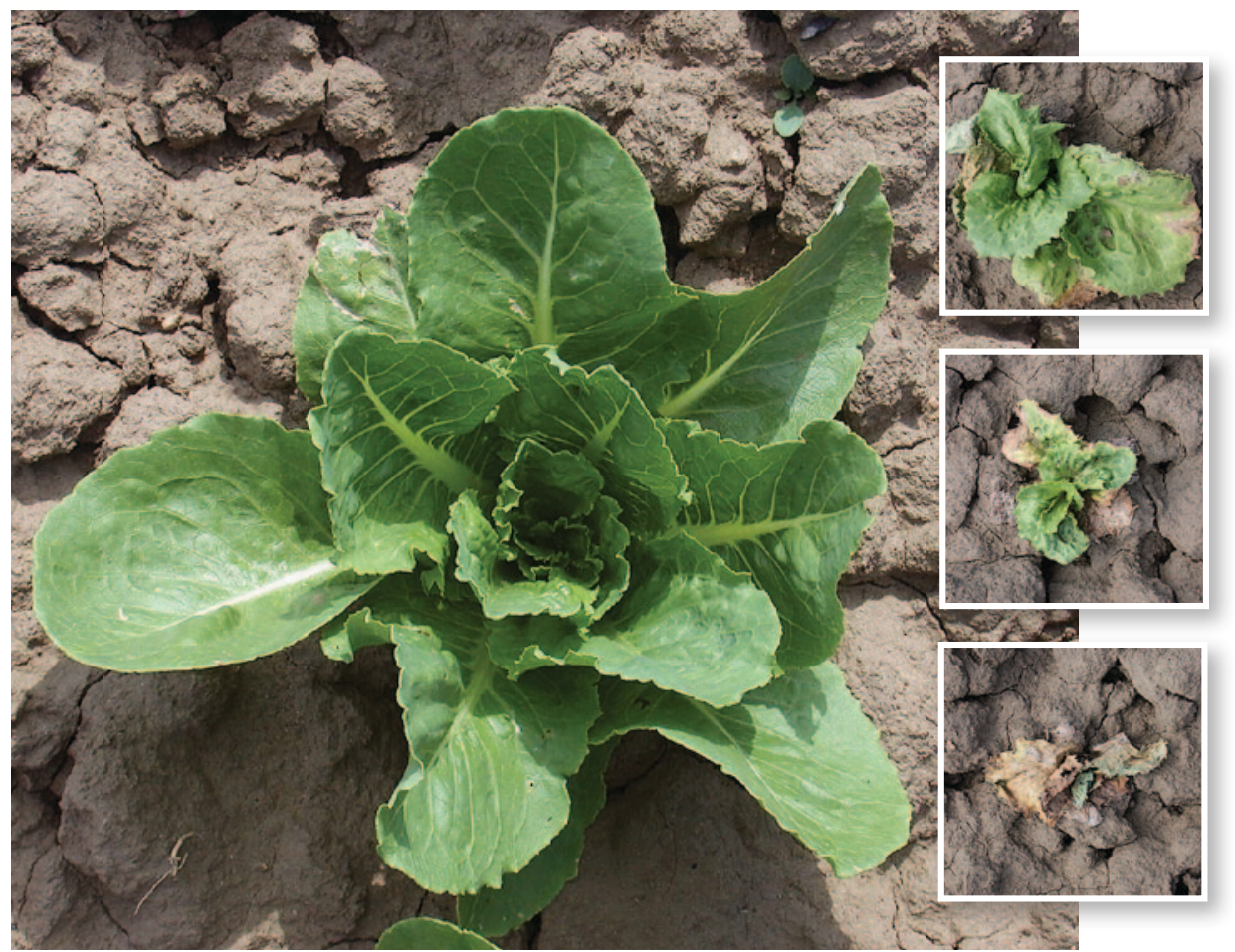

Lettuce cultivars have varying susceptibility to Fusarium wilt, a fungal disease. When grown in infested soils, Caesar was highly disease resistant. Inset, top, Grand Max and, middle and bottom, Early Queen were progressively less resistant.

in the root cortex and cause no visible damage to their host plant. However, some strains invade the water-conducting tissue (xylem) and restrict the flow of water and cause wilting.

The isolate of F. oxysporum recovered from the diseased California plants was pathogenic only on lettuce, not on any other crops tested (Hubbard and Gerik 1993). Host-specific, disease-causing strains of F. oxysporum are referred to as formae speciales (f. sp.) to distinguish them from nonpathogenic strains. The host-specific strain causing disease on lettuce is known as F. oxysporum $\mathrm{f}$. sp. lactucae.

The origin of the pathogenic strain causing Fusarium wilt in California lettuce is unknown, but it may have been introduced from overseas. The same pathogen has been affecting lettuce in Japan since 1955 (Matuo and Motohashi 1967). It may have been transported on lettuce seed, which can be contaminated with F. oxysporum f. sp. lactucae; for example, the pathogen has been recovered from commercial lettuce seed lots in Italy (Garibaldi et al. 2004). Fusarium wilt has recently appeared in many countries, including Iran, Taiwan, Italy, Portugal and Brazil.

When a lettuce plant affected by Fusarium wilt dies, the pathogen can produce survival structures (chlamydospores) within diseased tissue. Chlamydospores are incorporated into soil with crop residues, and they may survive there for one to several years, infecting the roots of any susceptible crop that is planted. Initially, California lettuce growers could avoid Fusarium wilt by not returning to affected fields. However, avoidance became increasingly difficult as F. oxysporum f. sp. lactucae spread in the San Joaquin Valley, probably in soil moved around on farming equipment. Soil transportation may have been how the pathogen became established in

Online: http://californiaagriculture.ucanr.org/ landingpage.cfm?article $=$ ca.v066n01p20\&fulltext=yes DOI: 10.3733/ca.v066n01p20 
Arizona and coastal California, where Fusarium wilt was recognized in 2001 and 2002, respectively.

\section{Survival in soil}

If the Fusarium wilt pathogen is established in a field, it may be possible to eradicate it through soil fumigation; the chances are best when the affected area is limited in size and can be treated thoroughly. Without intervention, an infestation will expand as infective propagules (spores or mycelium of the pathogen) are moved with soil during cultivation. Continued production of lettuce in an infested field requires careful management to minimize losses. Even if the pathogen can be eradicated, reintroduction remains a risk, and routine preplant fumigation is generally not an option because of costs and regulatory restrictions. Consequently, growers must rely on the attrition of inoculum that occurs naturally when nonsusceptible crops are grown instead of lettuce (i.e., crop rotation).

To estimate the longevity of pathogen propagules, we transported soil from a naturally infested commercial lettuce field in Arizona to establish microplots at the University of Arizona's Yuma Agricultural Center. Plots were maintained in a fallow condition (weed-free), and soil samples were taken at intervals over 34 months. Soil dilution plating was used to enumerate colony-forming units (CFUs) of F. oxysporum f. sp. lactucae, based on the pathogen's distinctive appearance on a selective growth medium (Scott, Gordon, et al. 2010). After 6 and 12 months, the inoculum density (number of CFUs per unit weight of soil) had declined

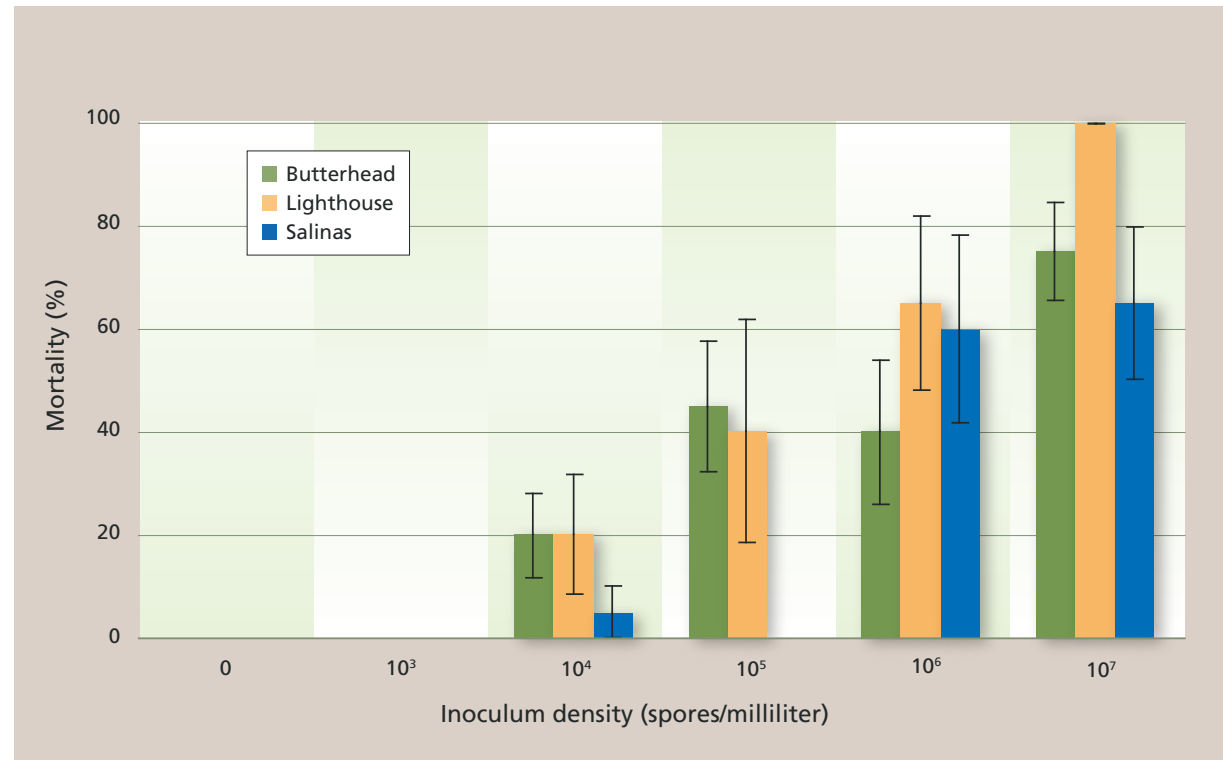

Fig.1. Mortality resulting from inoculations of lettuce seedlings with water (inoculum density $=0$ ) or one of five inoculum densities of the Fusarium wilt pathogen.

by $71 \%$ and $86 \%$, respectively. The decline in viability continued at a slower rate; after 34 months, F. oxysporum f. sp. lactucae was detectable at 482 CFUs per ounce (17 CFUs per gram), representing $0.5 \%$ of the starting population. We estimated the half-life (the time interval required for inoculum to decline to $50 \%$ of the original level) of the fungal population in soil to be $5.9 \pm 0.7$ months.

These results imply that keeping a field free of a susceptible crop for a year should dramatically reduce the density of pathogen inoculum - provided there is no significant reproduction on weeds or a rotation crop - but that the pathogen will likely persist at a low level for at least several years. The inoculum density that constitutes a threshold below which

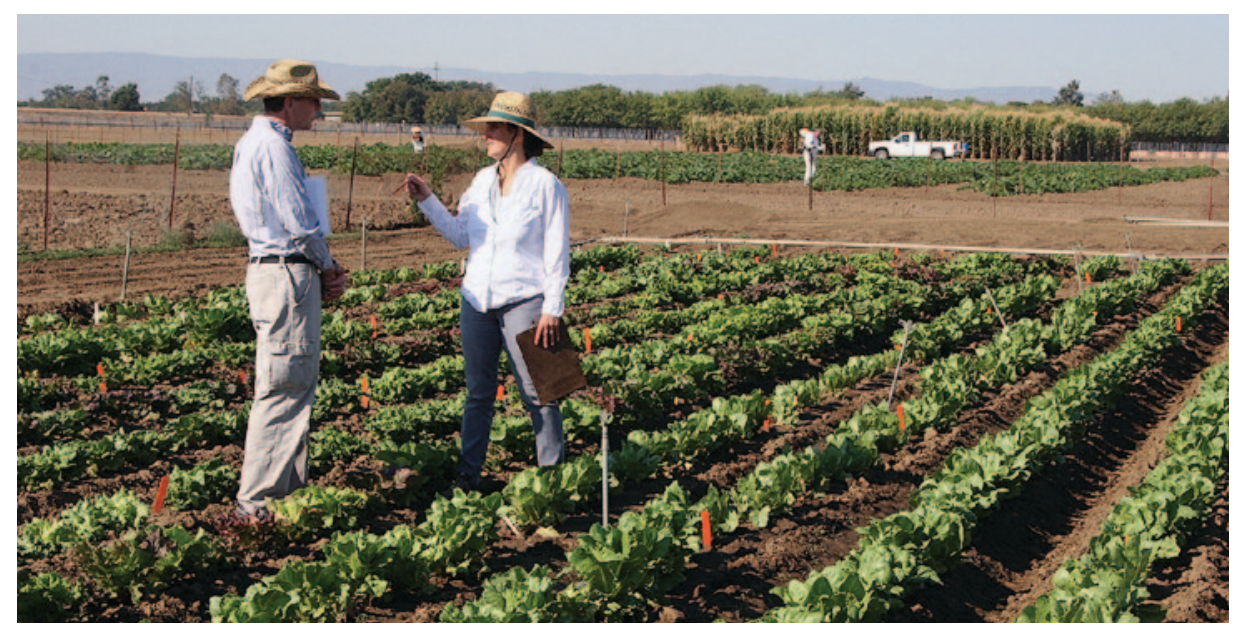

In trials conducted at UC Davis, crisphead, romaine and leaf lettuce were evaluated on a 4-point scale for susceptibility to Fusarium wilt. Above, co-authors Thomas Gordon (left) and Maria Truco. economic damage will not occur depends on other factors, particularly the inherent susceptibility of the crop and the level of inoculum to which it is exposed.

\section{Effect of inoculum density}

We tested the effect of inoculum density on the susceptibility of three lettuce cultivars using root-dip inoculations in a greenhouse trial. Seedling roots of the cultivars Butterhead, Lighthouse and Salinas were submerged in a suspension of pathogen spores at each of five different inoculum densities: $10^{3}, 10^{4}, 10^{5}, 10^{6}$ and $10^{7}$ spores per milliliter. Pathogen spores were obtained from a known virulent strain originally isolated from a diseased lettuce plant in California (Hubbard and Gerik 1993).

Inoculated seedlings of all three cultivars developed symptoms of Fusarium wilt, even at the lowest dose of $10^{3}$ spores per milliliter, although no mortality was observed at this level (fig. 1). No disease symptoms were observed in seedlings that were dipped in water rather than a spore suspension. Based on logistic regression, increasing the inoculum density significantly elevated the likelihood of mortality $(P<0.001)$. The cultivar Salinas appeared more resistant than the other two cultivars at both $10^{4}$ and $10^{5}$ spores per milliliter, but this difference was less evident at $10^{6}$ and $10^{7}$ spores per milliliter (fig. 1).

These results suggest that screening for resistance at $10^{5}$ spores per milliliter 
may provide better resolution of differences in susceptibility than higher inoculum levels. Most important is that such differences are predictive of how cultivars will respond under field conditions. If inoculation with $10^{5}$ spores per milliliter understates the disease pressure to which plants would likely be subjected in a naturally infested field, differences apparent at this inoculum level may be misleading. Conversely, higher inoculum levels may overstate natural disease pressures and therefore fail to detect useful levels of disease resistance.

\section{Predicting susceptibility}

To assess the relationship between cultivar response to seedling inoculations and susceptibility under field conditions, we established an infested plot on the Department of Plant Pathology research farm at UC Davis. Lab-reared inoculum of F. oxysporum f. sp. lactucae was incorporated into the soil in 2002, and successive crops of susceptible lettuce cultivars were grown for 3 years in order to ensure high levels of inoculum throughout the field. In 2006, seedlings of cultivars that differed in susceptibility to root-dip inoculations were transplanted into the infested field. The trial was replicated three times during the season. In each replication, plants were rated for disease severity on a scale of 1 to 4 , with 1 for no symptoms, 2 for mild stunting, 3 for severe stunting and some leaf yellowing or necrosis, and 4 for plant mortality.
Final disease severity ratings, taken 6 weeks after planting, were compared to ratings recorded for the same set of cultivars subjected to seedling root-dip inoculations at $10^{5}$ and $10^{6}$ spores per milliliter, using correlation analysis. The results showed the ranking of cultivars based on a root-dip assay to be highly and significantly correlated with rankings based on field trials. For root-dip assays using $10^{5}$ and $10^{6}$ spores per milliliter, Pearson correlation coefficients ranged from 0.844 to 0.893 , and from 0.792 to 0.826 , respectively, for three replications of the field trial. These findings indicate that correlations with susceptibility under field conditions were somewhat stronger when seedlings were inoculated with $10^{5}$ as opposed to $10^{6}$ spores per milliliter, but also that inoculations at either inoculum level reliably indicated differences in susceptibility to Fusarium wilt.

\section{Cultivar field trials}

Field trials revealed significant differences between cultivars in susceptibility to Fusarium wilt. At 3 weeks after planting, two leaf lettuce cultivars (Lolla Rossa and Red Rossa) and three romaine cultivars (Caesar, Green Forest and King Henry) had low disease-severity ratings and appeared resistant. Two crisphead lettuce cultivars (Beacon and Early Queen) were highly susceptible, and three other crisphead cultivars (Grand Max, Kahuna and Salinas) were intermediate between these extremes (fig. 2). Salinas was the

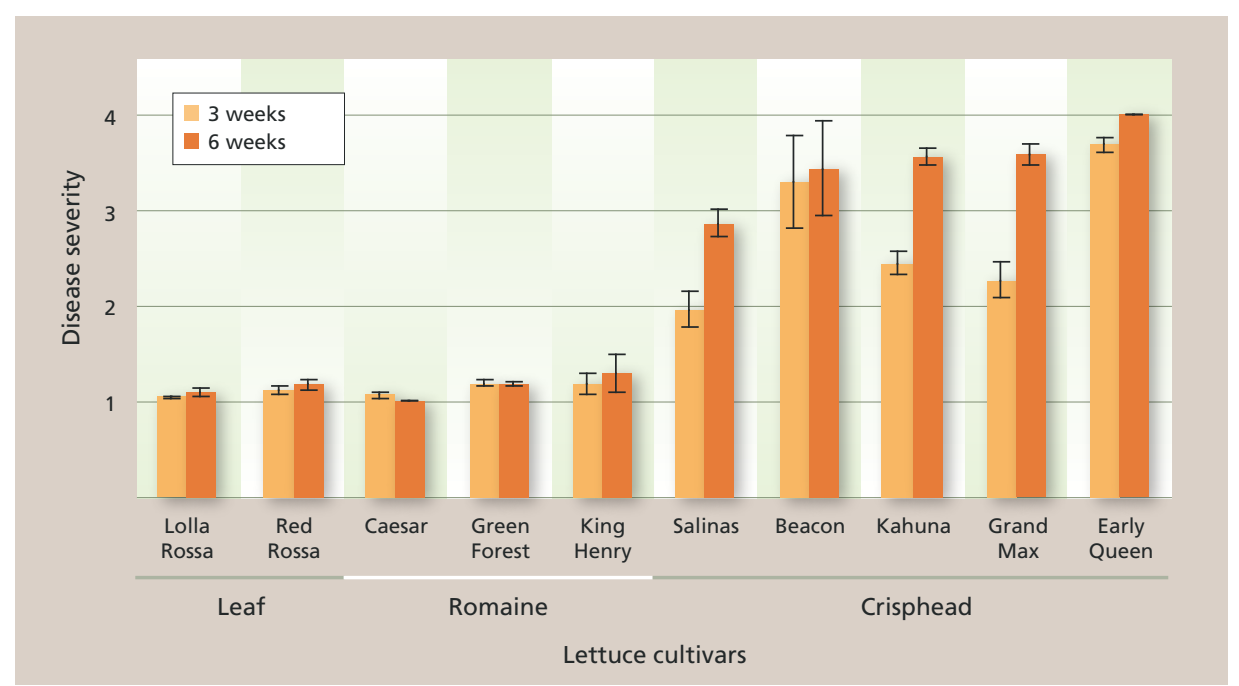

Fig. 2. Severity of symptoms of Fusarium wilt in two leaf lettuce cultivars, three romaine cultivars and five crisphead lettuce cultivars, 3 and 6 weeks after transplanting into a field infested with Fusarium wilt pathogen. Disease severity: 1 = no symptoms, 2 = mild stunting, 3 = severe stunting, some leaf yellowing or necrosis, 4 = plant mortality.

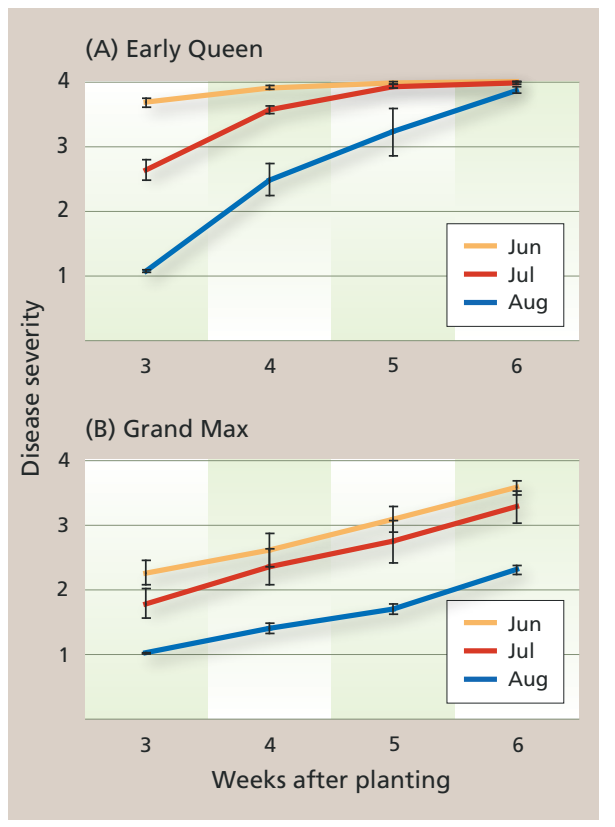

Fig. 3. Disease severity over time in three plantings (established in June, July and August) of crisphead lettuce cultivars (A) Early Queen and (B) Grand Max. Disease severity: $1=$ no symptoms, 2 = mild stunting, $3=$ severe stunting, some leaf yellowing or necrosis, $4=$ plant mortality.

most resistant of the crisphead lettuce cultivars tested by Hubbard and Gerik (1993) and suffered limited mortality from Fusarium wilt in a field trial in Arizona (Matheron et al. 2005).

By the final rating, 6 weeks after planting, differences among the crisphead lettuce cultivars had largely disappeared (fig. 2). Although Salinas and Grand Max are more resistant to Fusarium wilt than other crisphead lettuce cultivars, their level of resistance may be insufficient to prevent severe damage. On the other hand, leaf and romaine cultivars retained low severity ratings until the end of the season. However, Scott, Kirkpatrick, et al. (2010) found that some leaf and romaine cultivars tested under greenhouse conditions were severely damaged by Fusarium wilt, so there was not a consistent association between cultivar type and susceptibility.

\section{Effects of temperature}

In the field trials at UC Davis, disease developed more rapidly in the first (June) trial than in the second (July) and third (August) trials. This is apparent from a comparison of the rate at which disease severity increased in the susceptible cultivar Early Queen. In the June trial, mean 
disease severity for Early Queen was 3.7 (on a scale of 1 to 4 ) at 3 weeks after planting, compared to 2.6 and 1.1 at the same interval in the July and August plantings, respectively (fig. 3A). Disease severity was lower in the August trial throughout the evaluation period, until the final rating at 6 weeks after planting, when mortality was $100 \%$, or nearly so, regardless of planting date. On the other hand, for the Grand Max cultivar the differences between trials remained apparent even at the end of the season (fig. 3B).

Differences in disease severity corresponded to differences in temperatures, Air temperatures were highest during the June planting, with a mean daily high/low of $99^{\circ} \mathrm{F} / 59^{\circ} \mathrm{F}\left(37^{\circ} \mathrm{C} / 15^{\circ} \mathrm{C}\right)$. They were progressively lower during trials in July, $95^{\circ} \mathrm{F} / 55^{\circ} \mathrm{F}\left(35^{\circ} \mathrm{C} / 13^{\circ} \mathrm{C}\right)$, and August, $90^{\circ} \mathrm{F} / 52^{\circ} \mathrm{F}\left(32^{\circ} \mathrm{C} / 11^{\circ} \mathrm{C}\right)$. These findings suggest that higher temperatures may render lettuce more prone to damage from Fusarium wilt.

To look more directly at the effects of temperature on disease development, we conducted tests in controlled environment chambers set to a 14-hour

\section{Lettuce is grown throughout the year in} California and Arizona, and the risk of damage from Fusarium wilt is highest during the

\section{warmest periods.}

photoperiod and one of three temperature regimes: cool, day/night temperatures of $73^{\circ} \mathrm{F} / 64^{\circ} \mathrm{F}\left(23^{\circ} \mathrm{C} / 18^{\circ} \mathrm{C}\right)$; moderate, $82^{\circ} \mathrm{F} / 68^{\circ} \mathrm{F}\left(28^{\circ} \mathrm{C} / 20^{\circ} \mathrm{C}\right)$; or warm, $91^{\circ} \mathrm{F} / 73^{\circ} \mathrm{F}$ $\left(33^{\circ} \mathrm{C} / 23^{\circ} \mathrm{C}\right)$. Seed was sown into potting mix infested with the Fusarium wilt pathogen at 141,751 CFUs per ounce $\left(5 \times 10^{3}\right.$ CFUs per gram) (Scott, Gordon, et al. 2010).

One month after seeding, plants were rated for disease severity. The results confirmed a significant effect of temperature on the development of Fusarium wilt, with disease being most severe at the highest temperatures. Under cool conditions, even the susceptible cultivar Early Queen suffered relatively little damage, whereas it showed maximal disease severity at the highest temperature (fig. 4). A similar trend was evident for the cultivar Grand Max, although it was less severely affected than Early Queen at all tested temperatures. In contrast, the highly resistant cultivar Lolla Rossa remained healthy regardless of the temperature regime (fig. 4).

Observations in California's coastal lettuce-growing districts support the importance of temperature as a factor affecting development of Fusarium wilt. Fields in the Pajaro Valley and King City area have become infested with F. oxysporum f. sp. lactucae, and Fusarium wilt of lettuce has occurred in both areas. Whereas Fusarium wilt in the Pajaro Valley has remained insignificant, the incidence and severity of disease has increased in the King City area. In the Pajaro Valley, mean daily high temperatures during the main lettuce-growing season (May through October) remain below $73^{\circ} \mathrm{F}\left(23^{\circ} \mathrm{C}\right)$; corresponding temperatures in the King City area are $77^{\circ} \mathrm{F}\left(25^{\circ} \mathrm{C}\right)$ or above, reaching a high of $84^{\circ} \mathrm{F}\left(29^{\circ} \mathrm{C}\right)$ for a 3-month period (July through September) (table 1). Higher temperatures may help to explain the greater incidence and severity of Fusarium wilt in the King City area.

The effect of temperature on Fusarium wilt has important implications for disease management. Lettuce is grown throughout the year in California and Arizona, and the risk of damage from Fusarium wilt is highest during the warmest periods. Field trials conducted by Matheron et al. (2005) in Arizona showed a significant effect of planting date on the incidence of Fusarium wilt. The highest incidence ( $88 \%$ ) occurred in September plantings, which corresponded to a mean soil temperature of $79^{\circ} \mathrm{F}\left(26^{\circ} \mathrm{C}\right)$, whereas the lowest disease incidence $(1 \%)$ was in December plantings, when mean soil temperature was $57^{\circ} \mathrm{F}\left(14^{\circ} \mathrm{C}\right)$. These

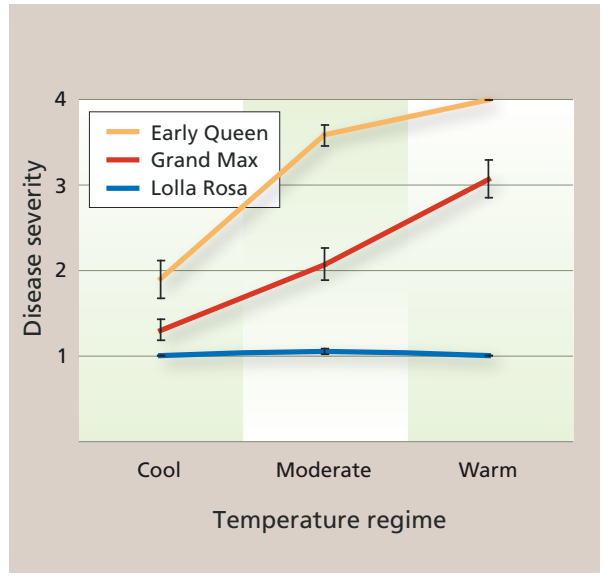

Fig. 4. Severity of Fusarium wilt symptoms in a leaf lettuce cultivar (Lolla Rossa) and two crisphead lettuce cultivars (Grand Max and Early Queen) maintained under three temperature regimes. Disease severity: 1 = no symptoms, $2=$ mild stunting, $\mathbf{3}=$ severe stunting, some leaf yellowing or necrosis, 4 = plant mortality.

findings indicate that losses to Fusarium wilt may be greatly reduced by not using susceptible cultivars during warm growing periods.

The effect of temperature on disease severity also has relevance to screening for resistance to Fusarium wilt. For example, when grown under cool conditions, many lettuce cultivars were essentially indistinguishable, whereas clear differences in susceptibility were apparent under warm conditions (Scott, Gordon, et al. 2010). Better resolution of differences in susceptibility should facilitate the process of identifying sources of resistance and transferring the determinants of resistance into other genetic backgrounds.

\section{Genetic improvements}

A continuing objective of our research is to understand the genetic basis of resistance and to elevate the resistance of

TABLE 1. Mean daily temperatures in coastal growing areas affected by Fusarium wilt

\begin{tabular}{|c|c|c|c|c|c|c|c|c|c|}
\hline \multicolumn{2}{|l|}{ Location } & Mar & Apr & May & Jun & Jul & Aug & Sep & Oct \\
\hline & & $\ldots$ & $\cdots \cdots$ & $\cdots \cdots$ & $\ldots{ }^{\circ}$ & C) $\cdots \cdots$ & $\ldots \ldots$ & $\cdots \cdots$ & $\ldots \ldots$ \\
\hline \multirow[t]{2}{*}{ King City* } & High & $\begin{array}{c}67 \\
(19.4)\end{array}$ & $\begin{array}{c}72 \\
(22.2)\end{array}$ & $\begin{array}{c}77 \\
(25.0)\end{array}$ & $\begin{array}{c}81 \\
(27.2)\end{array}$ & $\begin{array}{c}84 \\
(28.9)\end{array}$ & $\begin{array}{c}84 \\
(28.9)\end{array}$ & $\begin{array}{c}84 \\
(28.9)\end{array}$ & $\begin{array}{c}78 \\
(25.5)\end{array}$ \\
\hline & Low & $\begin{array}{c}38 \\
(3.3)\end{array}$ & $\begin{array}{c}40 \\
(4.4)\end{array}$ & $\begin{array}{c}45 \\
(7.2)\end{array}$ & $\begin{array}{c}48 \\
(8.9)\end{array}$ & $\begin{array}{c}50 \\
(10.0)\end{array}$ & $\begin{array}{c}51 \\
(10.5)\end{array}$ & $\begin{array}{c}48 \\
(8.9)\end{array}$ & $\begin{array}{c}44 \\
(6.7)\end{array}$ \\
\hline \multirow[t]{2}{*}{ Pajaro Valley† } & High & $\begin{array}{c}62 \\
(16.7)\end{array}$ & $\begin{array}{c}68 \\
(20.0)\end{array}$ & $\begin{array}{c}69 \\
(20.5)\end{array}$ & $\begin{array}{c}71 \\
(21.6)\end{array}$ & $\begin{array}{c}72 \\
(22.2)\end{array}$ & $\begin{array}{c}72 \\
(22.2)\end{array}$ & $\begin{array}{c}73 \\
(22.8)\end{array}$ & $\begin{array}{c}72 \\
(22.2)\end{array}$ \\
\hline & Low & $\begin{array}{c}41 \\
(5.0)\end{array}$ & $\begin{array}{c}43 \\
(6.1)\end{array}$ & $\begin{array}{c}48 \\
(8.9)\end{array}$ & $\begin{array}{c}50 \\
(10.0)\end{array}$ & $\begin{array}{c}52 \\
(11.1)\end{array}$ & $\begin{array}{c}52 \\
(11.1)\end{array}$ & $\begin{array}{c}50.9 \\
(10.5)\end{array}$ & $\begin{array}{c}49 \\
(9.4)\end{array}$ \\
\hline
\end{tabular}


crisphead lettuce cultivars to Fusarium wilt. To this end, we analyzed recombinant inbred lines (RILs) developed from a cross between the crisphead lettuce cultivar Salinas, which has moderate resistance to Fusarium wilt, and Valmaine, a highly resistant romaine cultivar.

RILs are populations derived from a cross between two inbred lines to produce an $F_{1}$ hybrid that is subsequently self-pollinated for several generations to capture and immortalize the variation segregating in the cross. A total of 147 RILs were tested for susceptibility in the infested plot at UC Davis during the summers of 2007 and 2008.

To analyze the genetics of resistance, we determined the segregation of 76 polymorphic Illumina GoldenGate SNP markers (Michelmore Laboratory 2011) to genetically characterize each RIL. SNP (single nucleotide polymorphism) markers are differences in the chromosomal DNA sequence that occur frequently in many genomes. Such markers allow the inheritance of each chromosomal region to be analyzed and correlated with segregating traits (e.g., disease resistance). Some traits are determined by and therefore inherited as single genes. However, many are determined by several genes that are located in multiple positions in the genome. These are known as quantitative trait loci (QTLs). Alternative versions of each QTL are referred to as alleles.

Analysis of the segregation of resistance relative to each SNP marker identified three QTLs for resistance to Fusarium wilt on chromosomal linkage groups (LGs) 1, 2 and 7. For the QTLs on LG1 and LG2, the Valmaine allele conferred resistance; on LG7, the Salinas allele was responsible for resistance. Although Valmaine has a high level of resistance compared to Salinas, our findings indicate that Salinas has a gene conferring a low level of resistance that is distinct from

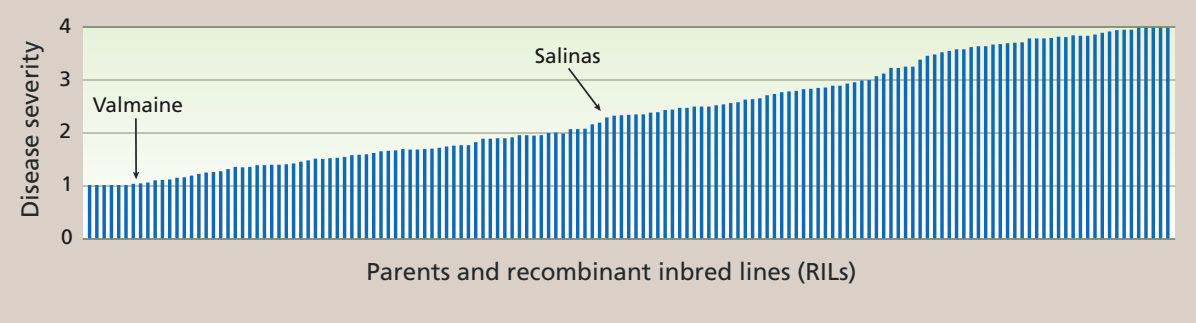

Fig. 5. Distribution of disease severity scores. Recombinant inbred lines with transgressive segregation for resistance were more resistant than Valmaine cultivar and lines with transgressive segregation for susceptibility showed more severe disease symptoms than Salinas cultuvar. Disease severity: 1 = no symptoms, 2 = mild stunting, 3 = severe stunting, some leaf yellowing or necrosis, 4 = plant mortality.

those in Valmaine, and that combining these positive alleles from both parents provides higher levels of resistance than is conferred by either parent. The more extreme resistance and susceptibility in some RILs - resulting from the combining of alleles from both parents such that some RILs manifest either greater susceptibility than Salinas or greater resistance than Valmaine - is known as transgressive segregation (fig. 5).

We have identified other resistant romaine and red leaf cultivars and started developing populations to determine the genetic basis of their resistance. Breeding is under way to transfer the resistance genes from Valmaine to crisphead types that will be aided by molecular markers linked to the QTL. The process is time consuming, so it will be several years before highly resistant crisphead cultivars are available.

\section{Reducing lettuce damage}

Damage from Fusarium wilt can be avoided by not growing a susceptible cultivar in a field with a history of the disease. Where the pathogen is present, disease severity is influenced by three factors: cultivar susceptibility, the abundance of pathogen inoculum and ambient temperatures during the growing season.
Highly resistant cultivars appear to remain healthy under all conditions, but for most cultivars - including all crisphead types that have been tested - disease severity increases with higher soil inoculum densities and warmer weather.

The risk of severe Fusarium wilt damage may be reduced by crop rotation to allow for the attrition of pathogen propagules in the soil, and by not growing susceptible cultivars during the warmest planting windows. In the future, highly resistant cultivars of multiple types will be available for vulnerable production areas and warm periods of the season.

J.C. Scott is Postdoctoral Researcher, T.R. Gordon is Professor, and S.C. Kirkpatrick is Staff Research Associate, Department of Plant Pathology, UC Davis; S.T. Koike is Plant Pathology Farm Advisor, UC Cooperative Extension, Monterey County; M.E. Matheron is Extension Plant Pathologist and Professor, School of Plant Sciences, University of Arizona, Yuma; and O.E. Ochoa is Senior Research Associate, M.J. Truco is Project Scientist, and R.W. Michelmore is Professor, Department of Plant Sciences, UC Davis.

The authors acknowledge financial support from the California Leafy Greens Research Board and thank Tom Kominek, Pauline Sanders and Richard Webb for technical assistance.

\section{References}

Citydata.com. 2011. Pajaro, California. www.city-data. com/city/Pajaro-California.htm Garibaldi A, Gilardi G, Gullino ML. 2004. Seed transmission of Fusarium oxysporum f. sp. lactucae. Phytoparasitica 32:61-5.

Hubbard JC, Gerik JS. 1993. A new wilt disease of lettuce incited by Fusarium oxysporum f. sp. lactucum forma specialis nov. Plant Dis 77:750-4
Matheron ME, McCreight JD, Tickes BR, Porchas M. 2005. Effect of planting date, cultivar and stage of plant de velopment on incidence of Fusarium wilt of lettuce in desert production fields. Plant Dis 89:565-70.

Matuo T, Motohashi S. 1967. On Fusarium oxysporum f. sp. lactucae $n$. f. causing root rot of lettuce. Trans Mycol Soc Japan 32:13-5.

Michelmore Laboratory. 2011. The Compositae Genome Project: Illumina GoldenGate SNP Analysis of Lettuce. Davis, CA. http://compgenomics.ucdavis.edu/compositae_SNP.php.
Scott JC, Gordon TR, Shaw DV, Koike ST. 2010. Effect of temperature on severity of Fusarium wilt of lettuce caused by Fusarium oxysporum f. sp. lactucae. Plant Dis 94:13-7.

Scott JC, Kirkpatrick SC, Gordon TR. 2010. Variation in susceptibility of lettuce cultivars to Fusarium wilt caused by Fusarium oxysporum f. sp. lactucae. Plant Pathol 59:139-46.

US Department of State. 2008. U.S. Weather. King City. http://countrystudies.us/united-states/weather/ California/king-city.htm. 